lymphatic leaks. Transl Androl Urol. 2020;9(S1):S104-S113. doi:10.21037/tau.2019.08.15

6. Pamarthi V, Pabon-Ramos WM, Marnell $V_{\text {, }}$ Hurwitz LM. MRI of the Central Lymphatic System: Indications, Imaging Technique, and PreProcedural Planning. Top Magn Reson Imaging. 2017:26(4):175-180.

doi:10.1097/RMR.0000000000000130
7. Munn LL, Padera TP. Imaging the lymphatic system. Microvasc Res. 2014;0:55-63. doi:10.1016/j.mvr.2014.06.006

8. Itkin M, Kucharczuk JC, Kwak A, Trerotola SO, Kaiser LR. Nonoperative thoracic duct embolization for traumatic thoracic duct leak: Experience in 109 patients. The Journal of Thoracic and Cardiovascular Surgery. 2010;139(3):584-590. doi:10.1016/j.jtcvs.2009.11.025

\title{
TÌNH TRANG DINH DƯỡNG CỦA BÊNH NHÂN SA SÚT TRÍ TUÊ ĐIỀU TRỊ NộI TRÚ TạI BỆNH VIỆN LÃO KHOA TRUNG ƯƠNG
}

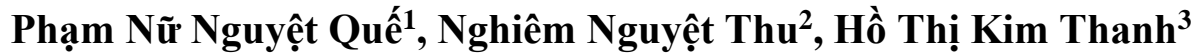

\section{TÓM TẮT}

Mục tiêu: Đánh giá tình trạng dinh dưỡng của bệnh nhân sa sút trí tuệ (SSTT) điều trị nội trú tại Bệnh viện Lão khoa Trung ương. Đối tượng và phương pháp: Nghiên cứu mô tả cắt ngang trên 106 bệnh nhân SSTT điều trị nội trú tại Bệnh viện Lão khoa Trung ương trong thời gian từ tháng 3 năm 2020 đến tháng 7 năm 2021. Số liệu được thu thập bằng hỏi bệnh, các bộ câu hỏi đánh giá, ghi nhận theo hồ sơ bệnh án của bệnh nhân để thu thập thông tin về tình trạng dinh dưỡng của bệnh nhân. Tình trang dinh dưỡng được đánh giá dựa vào 2 công cụ là MìA (Mini Nutrition Assessment) và GLIM (Global Leadership Initiative Malnutrition). Kết quả: Tuổi trung bình của đối tượng nghiên cứu là79,5 \pm 8,4 (61-97), tỷ lê nũ $52,8 \%$ và nam là $47,2 \%$. Bênh nhân vào viên vì nhiếm trùng là lý do phổ biến trong đó viêm phổi chiếm tỉ lê cao nhất $45,3 \%$. Tỷ lệ suy dinh dưỡng(SDD) theo MNA là $66,0 \%$, theo GLIM là $62,0 \%$. Ti lệ SDD theo phương pháp đánh giá MNA ở nhóm bệnh nhân SSTT giai đoạn nặng chiếm $73,0 \%$ với $p<0.001$, theo tiêu chuẩn GLIM là $69,7 \%$ với $p<0.05$. Kết luận: Tỷ lệ SDD cao ở bênh nhân SSTT, SSTT giai đoan càng nặng thì tỉ lệ càng cao. Do vậy, đánh giá dinh dưỡng và có kế hoạch can thiệp dinh dưỡng sớm, cần được chú ý đối với bênh nhân SSTT. cao tuổi

Tư khóa: Suy dinh dưỡng, sa sút trí tuệ, người

\section{SUMMARY}

\section{THE NUTRITIONAL STATUS OF DEMENTIA INPATIENTS AT THE NATIONAL GERIATRIC HOSPITAL}

Objective: To assess the nutritional status of dementia inpatients at the National

Bệnh viện Hữu Nghị

Bệnh viện Lão khoa Trung ương

Trường Đai hoc Y Hà Nội

Chịu trách nhiệm: Pham Nữ Nguyệt Quế

Email: nguyetque050277@gmail.com

Ngày nhận bài: 20/8/2021

Ngày phản biên khoa họ: 20/9/2021

Ngày duyệt bài: 1/10/2021
GeriatricHospital(NGH). Subjects and methods: A cross - sectional study on 106 dementia inpatients at the NGHfrom March 2020 to July 2021. The data was collected by interviewing care-givers, bymedical records on the nutritional status of the patient. Nutritional status is assessed on MNA and GLIM tools. Result: The average age was $79.5 \pm 8.4$ years (61.0-97.0 yrs). The proportion of female was $52.8 \%$, that of male was $47.2 \%$. The main admission reason is infection, pneumonia is the highest $(45,3 \%)$. The prevalence of malnutrition was $66.0 \%$ and $62.0 \%$ according to MNA and GLIM respectively. The prevalence of malnutrition among severe dementia was $73.0 \%$ according to MNA ( $p<0.001$ ), and was $67.9 \%$ according to GLIM ( $p<0.05$ ). Conclusion: The prevalence of malnutrition is high among dementia patients, the more severe of dementia, higher prevalence of malnutrition.It should be paid moreattention in nutrition assessment and early nutrition interventions for dementia patients.

Keyword: malnutrition, dementia, the elderly

\section{I. ĐĂT VẤN ĐỀ}

Theo báo cáo của hiệp hội Alzheimer thế giới dự kiến năm 2030sẽ có khoảng hơn 80 triệu người bị sa sút trí tuệ (SSTT), và 150 triệu người bênhvào năm 2050. Khu vực châu Á nắm 2030 có 42,71 triệu người và năm 2050 có khoảng 81,75 triệu người bệnh [1]. SSTT đặc trưng bởi sự suy giảm chức năng nhận thức ảnh hưởng đến hoat động hàng ngày diễn biến kéo dài nhiều nằm, bênh nhân dân sống phụ thuộc vào người chăm sóc và cuối cùng tử vong chủ yếu do nhiễm trùng.

Tình trang thiếu dinh dưỡng đặc biêt phổ biến ở bệnh nhân SSTT tại tất cả các khu vực trên thế giới. Việc giảm cân thường xảy ra từ trước khi bắt đầu có SSTT và tăng dần trong suốt quá trình tiến triển bênh. Tai Viêt nam, bênh nhân SSTT hầu hết được chăm sóc ở cộng đồng, thường chỉ nhập viện điều trị nội trú khi có bệnh lý cấp tính kèm theo hoăc vào viên điều trị vì bệnh khác, do đó giảm khẩu phần ăn là vấn đề 
thường gặp của bệnh nhân sa sút trí tuệ đang điều trị nội trú. Theo 1 nghiên cứu ở Trung Quốc thì tỉ lệ SDD theo MNA là $58,4 \%$ [2].

SDD có liên quan đến nhiều kết quả lâm sàng bất lợi, bao gồm thời gian nằm viện dài hơn, tăng tỷ lệ mắc bệnh, tử vong và tăng viện phí. Việc chẩn đoán SDD và can thiệp dinh dưỡng sớm, phù hợp ở bệnh nhân nhập viện là rất quan trọng. Việt Nam còn ít các nghiên cứu đánh giá về tình trạng dinh dưỡng ở bệnh nhân SSTT nằm viện. Do vậy, chúng tôi tiến hành nghiên cứu đề tài này với mục tiêu: Đánh giá tỉnh trạng dinh dướng của bệnh nhân sa sút trí tuệ điều trị nội trú tại Bệnh viện Lão khoa Trung ương năm 2020-2021.

\section{II. ĐỐI TƯỢNG VÀ PHƯƠNG PHÁP NGHIÊN CỨU \\ 2.1. Đối tượng nghiên cứu \\ Tiêu chuẩn lựa chọn}

- Tất cả các bệnh nhân từ 60 tuổi trở lên được chẩn đoán SSTT do nguyên nhân Alzheimer hoặc do nguyên nhân mạch máu theo tiêu chuẩn DSM- V điêu trị nội trú tại Bệnh viện Lão khoa Trung ương (ghi nhận theo bệnh án) trong vòng 72 giờ tính từ khi vào viện.

- Tự nguyện tham gia nghiên cứu hoặc có sự đồng ý của người thân.

\section{Tiêu chuân loại trừ:}

- SSTT do các nguyên nhân khác

- Đối tượng hoặc người nhà không đồng ý tham gia nghiên cứu

\subsection{Thiết kế nghiên cứu}

Thiết kế nghiên cứu: Mô tả cắt ngang.

2.3. Cỡ mẫu nghiên cứu:

Phương pháp chọn mẫu: Là các bệnh nhân chẩn đoán SSTT do nguyên nhân Alzheimer hoăc do nguyên nhân mạch máu theo tiêu chuẩn DSM- $V$ và điều trị nội trú tại Bệnh viện Lão khoa Trung ương trong thời gian tiến hành nghiên cứu.

Cỡ mẩu: Được tính theo công thức cho nghiên cứu mô tả tính ra $\mathrm{n}=87$. Trong nghiên cứu của chúng tôi lấy 106 (dự phòng một số đối tượng nghiên cứu bỏ cuộc).

2.4. Quy trình nghiên cứu, kỹ thuật và

\section{KẾT QUẢ NGHIÊN CứU}

\section{1. Đăc điểm chung}

Bảng 1. Đặc điểm đối tượng nghiên cứu và người chăm sóc

\begin{tabular}{|c|c|c|c|c|}
\hline \multicolumn{2}{|c|}{ Đặc điếm nhấn khấu học } & $\mathbf{n}$ & Trung vị (min-max) & \% \\
\hline \multirow{3}{*}{ Tuổi } & Chung & 106 & $79,5 \pm 8,4(61,0-97,0)$ & \\
\cline { 2 - 5 } & $60-69$ & 12 & & 11,3 \\
\cline { 2 - 5 } & $70-79$ & 41 & & 38,7 \\
\cline { 2 - 5 } & $\geq 80$ & 53 & & 52,0 \\
\hline \multirow{2}{*}{ Giới } & Nữ & 56 & & 47,2 \\
\hline
\end{tabular}

công cụ thu thập thông tin. Nghiên cứu mô tả cắt ngang trên 106 bệnh nhân sa sút trí tuệ điều trị nội trú tại Bệnh viện Lão khoa Trung ương trong thời gian từ tháng 3 năm 2020 đến tháng 7 năm 2021.

Tất cả các đối tượng nghiên cứu được tiến hành thu thập số liệ̉u nghiên cứu thông qua bệnh án nghiên cứu được thiết kế sẵn gồm có: hành chính, tiền sử bệnh tật, thời gian mắc bệnh, chiều cao, cân nặng, BMI, chẩn đoán, các xét nghiệm cận lâm sàng. Xác định tình trạng dinh dưỡng theo công cụ đánh giá dinh dưỡng MNA và theo tiêu chuẩn GLIM.

\section{Cách đánh giá:}

- Phân loại BMI (Theo tổ chức y tế thế giới năm 2000): Bình thường: 18,5 - 24,9, Gầy/SDD/ thiếu năng lượng trường diễn: < 18,5, Thửa cân $>25,0$, Béo phì > 30,0

- Theo MNA (Mini Nutrition Assessment) đánh giá dinh dưỡng tối thiểu

12-14 điểm: Tình trạng dinh dưỡng bình thường 8-11 điểm: Nguy cở suy dinh dưỡng

0-7 điểm: Suy dinh dưỡng.

- Theo GLIM (Global Leadership Initiative Malnutrition):

- Chẩn đoán SDD khi có tiêu chuẩn biểu hiện và 1 tiêu chuẩn nguyên nhân:

+ Tiêu chuẩn biểu hiện: $B M I<18,5$ nếu $<70$ tuổi hoặc $B M I<20$ nếu $\geq 70$ tuổi.

+ Tiêu chuẩn nguyên nhân:

*Tình trạng viêm cấp tính hoặc bệnh mạn tính.

*Giảm khẩu phần ăn: giảm $<50 \%$ nhu cầu dinh dưỡng theo khuyến nghị trên 1 tuần hoặc bất kỳ giảm khẩu phần nào kéo dài trên 2 tuần hoặc bất kỳ tình trạng tiêu hóa mạn tính gây ảnh hưởng hấp thu thực phẩm.

2.5. Các biến số nghiên cứu: Tuổi, giới, trình độ học vấn, nơi sinh sống, các biến định lượng, các biến định tính

2.6. Xử lý số liệu. Nhập liệu và xử lý số liệu bằng phần mềm SPSS 20.0. Tính giá trị trung bình, tî lệ mắc

2.7. Đạo đức nghiên cứu. Nghiên cứu đảm bảo các vấn đề về đạo đức trong nghiên cứu y sinh. 
VIETNAM MEDICAL JOURNAL N²2 - OCTOBER - 2021

\begin{tabular}{|c|c|c|c|c|}
\hline \multirow{2}{*}{ Vùng địa lý } & Nông thôn & 43 & & 40,6 \\
\hline & Thành thị & 63 & & 59,4 \\
\hline \multirow{2}{*}{ Nghề nghiệp } & Lao động chân tay & 56 & & 43,4 \\
\hline & Lao động trí óc & 60 & & 56,6 \\
\hline Thời gian phát hiện bệnh (năm) & & 106 & $3,4 \pm 2,7(1,0-13,0)$ & \\
\hline \multirow{3}{*}{ Giai đoạn SSTT } & Nặng & 89 & & 84,0 \\
\hline & Vừa & 11 & & 10.3 \\
\hline & Nhe & 6 & & 5.7 \\
\hline \multirow{2}{*}{$\begin{array}{l}\text { Hoạt động chức năng } \\
\text { hàng ngày (ADL) }\end{array}$} & Bình thường & 34 & & 32,1 \\
\hline & Suy giảm & 72 & 67,9 & \\
\hline \multirow{2}{*}{$\begin{array}{l}\text { Hoạt động chức năng hàng } \\
\text { ngày có phương tiện (IADL) }\end{array}$} & Bình thường & 26 & & 24,5 \\
\hline & Suy giảm & 80 & & 75,5 \\
\hline \multirow[t]{6}{*}{ Lý do vào viện } & Viêm phối & 48 & & 45,3 \\
\hline & Loạn thần & 20 & & 18.9 \\
\hline & Tai biến mạch não & 14 & & 13.2 \\
\hline & Loét tì đè & 12 & & 11.3 \\
\hline & Té ngã & 2 & & 1.9 \\
\hline & Bệnh khác & 10 & & 9.4 \\
\hline Thời gian nằm viên (ngày) & & & $47,4 \pm 21,3$ & \\
\hline Tống chi phí điêuu trị (triệu VND) & & & $18,7 \pm 44,9(0,8-261,3)$ & \\
\hline $\begin{array}{l}\text { Tuối trung bình của } \\
\text { người chăm sóc chính }\end{array}$ & & & $\begin{array}{l}65,0 \pm 12,4 \\
(35,0-91,0)\end{array}$ & \\
\hline
\end{tabular}

Bảng 1 cho thãy tuổi trung bình trong nghiên cứu này là 79,5, dao động từ 61 đến 97 tuổi. Nhóm người bệnh trên 80 tuổi chiếm tỷ lệ cao nhất $(50 \%)$, không có sự khác biệt về giới tính. Những người trước đây làm nghề nghiệp lao động chân tay chiếm tỷ lệ $56,6 \%$. Thời gian phát hiện bệnh trung bình là 3,4 năm, trong đó $84,0 \%$ ở giai đoạn nặng. Tỷ lệ người có suy giảm hoạt động chức năng hàng ngày theo $A D L$ là $67,9 \%$ suy giảm, theo IADL là $75,5 \%$ suy giảm.

Trong các nguyên nhân nhập viện, viêm phổi chiếm tỳ lệ cao nhất (45,3\%), sau đó đến nguyên nhân nhập viện do loạn thần $(18,9 \%)$. Chi phí điều trị trung bình cho bệnh nhân là 18,7 triệu đồng, thời gian nằm viện trung bình là 47,4 ngày.

3.2. Tình trạng dinh dưỡng của bệnh nhân

Bảng 2. Đặc điểm nhân trắc của bệnh nhân lúc nhập viện

\begin{tabular}{|c|c|c|c|}
\hline $\begin{array}{c}\text { Các chỉ số } \\
\text { nhân trắc }\end{array}$ & & $\overline{\boldsymbol{x}} \pm$ SD & Min-Max \\
\hline $\begin{array}{c}\text { Cân nănn } \\
(\mathrm{kg})^{*}\end{array}$ & Nam & $47,7 \pm 7,5$ & $31,0-63,0$ \\
\cline { 2 - 4 } & Nữ & $44,7 \pm 9,4$ & $27,0-64,0$ \\
\hline $\begin{array}{c}\text { Chiêu cao } \\
(\mathrm{cm})^{*}\end{array}$ & Nam & $158,8 \pm 5,7$ & $145,0-168,0$ \\
\cline { 2 - 4 } & Nữ & $149,3 \pm 6,1$ & $140,0-168,0$ \\
\hline BMI $\left(\mathrm{kg} / \mathrm{m}^{2}\right)$ & & $19,3 \pm 3,0$ & $12,9-26,9$ \\
\hline $\begin{array}{c}\text { Chu vi vòng } \\
\text { cánh tay(cm) }\end{array}$ & & $23,3 \pm 3,0$ & $18,0-32,0$ \\
\hline $\begin{array}{c}\text { Chiêuu dài cằng } \\
\text { chân }(\mathrm{cm})\end{array}$ & & $46,1 \pm 3,2$ & $40,0-53,0$ \\
\hline
\end{tabular}

*Cân nặng và chiều cao gián tiếp (khi không đo được cân nặng trực tiếp) ước tính từ chiều dài cẳng chân và chu vi vòng cánh tay.
Bảng 2 cho thấy ở thời điểm nhập viện, cân nặng trung bình của đối tượng nghiên cứu thấp (nam là $47,7 \pm 7,5$ và nữ là $44,7 \pm 9,4 \mathrm{~kg}$ ). Chiều cao trung bình của nam là $158,8 \pm 5,7 \mathrm{~cm}$, nữ là $149,3 \pm 6,1 \mathrm{~cm}$. Chiều cao đầu gối trung bình là $46,1 \pm 3,2 \mathrm{~cm}$, chu vi vòng cánh tay trung bình là $23,3 \pm 3,0 \mathrm{~cm}$. BMI trung bình là $19,3 \pm 3,0 \mathrm{~kg} / \mathrm{m}^{2}$.

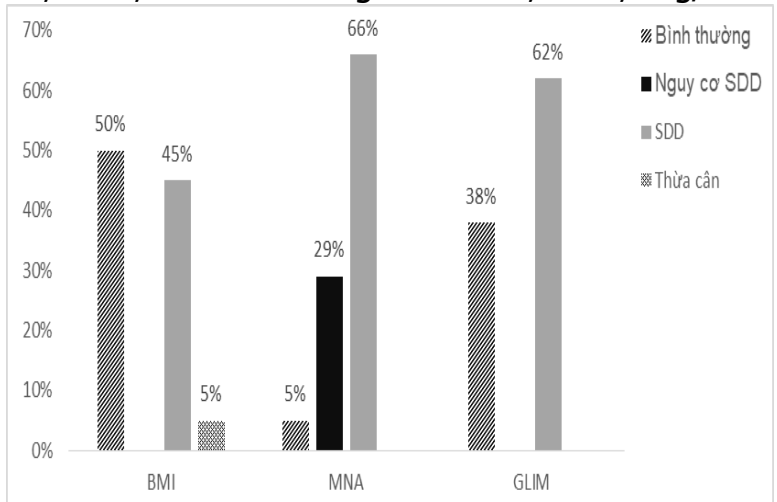

Biểu đồ 1. Tình trạng dinh dưỡng của bệnh nhân sa sút trí tuê**

*Phân loại theo BMI: Thừa cân, bình thường, Gày/suy dinh dưỡng. Phân loại theo MNA: bình thường, nguy cơ SDD, SDD. Phân loại theo GLIM: bình thường và SDD

Biểu đồ 1 cho thấy nễu theo phân loại của Tổ chức y tế thế giới, bệnh nhân có BMI bình thường chiếm $50,0 \% \quad(n=53)$, bệnh nhân gầy/suy dinh dưỡng/thiếu năng lượng trường diễn chiếm $45 \%(n=48)$, bệnh nhân thừa cân béo phì chiếm $5 \%(n=4)$. Theo phân loại $M N A$, 
có $66 \%$ bệnh nhân trong nghiên cứu có suy dinh dưỡng, $29 \%$ số bệnh nhân có nguy cơ suy dinh dưỡng, chỉ có $5 \%$ bình thường. Theo tiêu chuẩn
GLIM, có $62 \%$ bệnh nhân trong nghiên cứu có suy dinh dưỡng, và $38 \%$ bệnh nhân không suy dinh dưỡng.

3.4. Liên quan giữa tình trạng dinh dưỡng với một số yêu tố:

Bảng 3. Tỉnh trạng dinh dưỡng theo GLIMvới mức độ sa sút trí tuệ

\begin{tabular}{|c|c|c|c|c|c|c|}
\hline \multirow{3}{*}{$\begin{array}{l}\text { Mức độ sa } \\
\text { sút trí tuệ }\end{array}$} & \multicolumn{4}{|c|}{ Đánh giá dinh dưỡng theo GLIM } & \multirow{2}{*}{\multicolumn{2}{|c|}{ Chung }} \\
\hline & & & & & & \\
\hline & $\mathbf{n}$ & $\%$ & $\mathbf{n}$ & $\%$ & $\mathbf{n}$ & $\%$ \\
\hline Nặng & 62 & 69,7 & 27 & 30,3 & 89 & 100 \\
\hline Vừa & 3 & 27,3 & 8 & 72,7 & 11 & 100 \\
\hline Nhẹ & 1 & 16,7 & 5 & 83,3 & 6 & 100 \\
\hline
\end{tabular}

Bảng 3 cho thấy theo tiêu chuấn GLIM thì tỷ lệ SDD trong nhóm bệnh nhân SSTT giai đoạn nặng cao hơn các nhóm còn lại có ý nghĩa thống kê với $\mathrm{p}<0,05$

Bảng 4. Tinh trạng dinh dưỡng theo thang điểm MNA với 1 số yếu tố

\begin{tabular}{|c|c|c|c|c|c|c|c|c|c|}
\hline \multirow{3}{*}{\multicolumn{2}{|c|}{ Yếu tố liên quan }} & \multicolumn{8}{|c|}{ Đánh giá dinh dưỡng theo MNA } \\
\hline & & \multicolumn{2}{|c|}{ SDD } & \multicolumn{2}{|c|}{ Nguy cơ SDD } & \multicolumn{2}{|c|}{ Không SDD } & \multicolumn{2}{|c|}{ Chung } \\
\hline & & $\mathbf{n}$ & $\%$ & $\mathbf{n}$ & $\%$ & $\mathbf{n}$ & $\%$ & $\mathbf{n}$ & $\%$ \\
\hline \multirow{2}{*}{ Tuổi } & $<80$ tuối & 23 & 43,4 & 26 & 49.1 & 4 & 7,5 & 53 & 100 \\
\hline & $\geq 80$ tuối & 47 & 88,7 & 5 & 9,4 & 1 & 1,9 & 53 & 100 \\
\hline \multirow{3}{*}{$\begin{array}{c}\text { Mức độ } \\
\text { SSTT }\end{array}$} & Nặng & 65 & 73,0 & 21 & 23,6 & 3 & 3,4 & 89 & 100 \\
\hline & Vừa & 3 & 27,3 & 7 & 63,6 & 1 & 9,1 & 11 & 100 \\
\hline & Nhẹ & 2 & 30,3 & 3 & 50,0 & 1 & 16,7 & 6 & 100 \\
\hline \multirow[t]{2}{*}{ RL nuốt } & Có & 64 & 78,0 & 16 & 19,5 & 2 & 2,4 & 82 & 100 \\
\hline & Không & 6 & 25,0 & 15 & 62,5 & 3 & 12,5 & 24 & 100 \\
\hline \multicolumn{10}{|c|}{ p (Phi and Cramer's V tests) $<0,05$} \\
\hline \multirow{2}{*}{ Giới } & Nam & 37 & 74,0 & 13 & 26,0 & 0 & 0,0 & 50 & 100 \\
\hline & Nũ̃ & 33 & 58,9 & 18 & 32,2 & 5 & 8,9 & 56 & 100 \\
\hline \multicolumn{10}{|c|}{$\mathrm{p}$ (Phi and Cramer's V tests) $>0,05$. } \\
\hline
\end{tabular}

Bảng 4 cho thấy theo phương pháp MNA, bệnh nhân trên 80 tuổi trong nghiên cứu có tỷ lệ suy dinh dưỡng cao hơn nhóm còn lại, sự khác biệt có ý nghĩa thống kê với $p<0,05$. Khổng có sự khác biệt có ý nghĩa thống kê về tỷ lệ SDD giữa bệnh nhân nam và nữ trong nghiên cứu. Nhóm bệnh nhân SSTT nặng có tỷ lệ SDD cao hơn nhóm còn lại, sự khác biệt là có ý nghĩa thống kê với $p<0,05$. Nhóm bệnh nhân có triệu chứng rối loạn nuốt có tỷ lệ suy dinh dưỡng cao hơn nhóm bệnh nhân còn lại, sự khác biệt có ý nghĩa thống kê $(p<0,05)$.

\section{BÀN LUÂN}

Suy dinh dương phổ biến ở người bệnh SSTT, giai đoạn SSTT càng nặng, tỷ lệ SDD càng cao. Tuổi của nhóm đối tượng tương đối cao, trung bình 79,5 tuổi, cao hơn nghiên cứu của Nguyễn Thanh Bình năm 2018 là (78 tuổi)[3].

Bệnh nhân nữ chiếm tỷ lệ cao hơn so với nam $(52,8 \%$ so với $47,2 \%)$. Tỷ lệ nữ nhiều hơn nam tương tự với các nghiên cứu Việt Nam và trên thế giới. Sự khác biệt này được lý giải là tuổi thọ của nữ giới cao hơn nam giới ở hầu hết các quốc gia trên thế giới.
Nghề nghiệp người bệnh trước khi mắc bệnh liên quan đến lao động chân tay như: nông dân, công nhân, nội trợ, nghề tự do chiếm 43,4\% bệnh nhân. Trình độ học vấn cao, lao động trí óc thường xuyên có ý nghĩa làm chậm sự khởi phát hoăc làm giảm tỷ lệ mắc bệnh Alzheimer, tuy nhiên không ảnh hưởng đến quá trình tiến triển khi đã mắc bệnh. Trong nghiên cứu của chúng tôi tỷ lệ bệnh nhân lao động trí óc có tỉ lệ mắc bệnh cao hơn $(56,6 \%)$ có thể do đối tượng nghiên cứu của chúng tôi có cả SSTT do nguyên nhân mạch máu, theo 1 số nghiên cứu trong và ngoài nước thấy bệnh nhân SSTT do nguyên nhân mạch máu chủ yếu gặp ở bệnh nhân lao động trí óc.

Tuổi trung bình của người chăm sóc chính trong nghiên cứu này cao hơn so với kết quả nghiên cứu của Nguyễn Thanh Bình và 1 số nghiên cứu ở Viêtt Nam, tương đương với nghiên cứu tại Hoa Kỳ là 63 tuổi [4].

Nguyên nhân nhập viện của bệnh nhân SSTT chủ yếu là do nhiếm trùng với viêm phổi chiếm tỉ lệ cao nhất, sau đó là loạn thần, tai biến mạch não, loét. Điều này cũng phù hợp với nhiêu 
nghiên cứu tại Đài Loan là năm nguyên nhân hàng đầu làm nhập viện thường xuyên trong bệnh Alzheimer là hội chứng lú lẫn cấp, tai biến mạch não mới, viêm phổi, gãy xương và nhiễm khuẩn tiết niệu [5]. Bệnh nhân vào viện chủ yếu là giai đoạn nặng và trung bình,cũng phù hợp với một số nghiên cứu khác trên thế giới.

Theo phân loai tình trang dinh dưỡng của Tổ chức $Y$ tế thế giới, tỷ lệ nhóm $B M I<18,5$ chiếm tỷ lệ $45 \%$ và nhóm $B M I \geq 25$ chiếm tỷ lệ $5 \%$. Như vậy nghiên cứu cho thây $45 \%$ người bệnh thiếu năng lượng trường diễn. Tỷ lệ thiếu năng lượng trường diễn trong nghiên cứu này cao ( $45 \%$ so với $21,5 \%$ ) trong khi tỷ lệ người bệnh có $B M I \geq$ 25 thấp hơn (5\% so với 14,6\%) nghiên cứu của Vũ Thị Thu Hà tiến hành trên 288 bệnh nhân điều trị nội trú ở tất cả các khoa tại bệnh viện Lão khoa Trung ương năm 2016 với độ tuổi trung bình 77,1 tuổi [6] và cao hơn nghiên cứu của Nguyễn Thanh Bình trên đối tượng bệnh nhân SSTT khám ngoại trú tại bệnh viện, với tỷ lệ SDD là $32,2 \%$ $(n=99)$. Tỷ lệ trong nghiên cứu này cũng cao hơn kết quả của nghiên cứu được tiến hành trên 120 bệnh nhân $\geq 60$ tuổi ở Bệnh viện Phục hồi chức nằng ở Hong Kong năm 2005 (16,7\%) [2].

Tỷ lệ suy dinh dưỡng đánh giá theo công cụ MNA là $66, \%$, nguy cơ SDDlà $29,0 \%$ và chỉ có $5 \%$ là bình thường. Tỷ lệ SDD theo phương pháp MNA của nghiên cứu này cao hơn so với trong nghiên cứu của Vũ Thị Thu Hà tại Bệnh viện Lão khoa trên người bệnh nội trú các chuyên khoa $(66,0$ so với $43,4 \%)$ trong nghiên cứu của chúng tôi là bệnh nhân SSTT, tuối cao hơn, với $84 \%$ SSTT giai đoạn nặng, có rối loạn nuốt hoặc mất răng, nhai kém nển khẩu phần ăn giảm từ trước khi vào viện[6]. Tỉ lệ này của chúng tôi cao hơn các nghiên cứu khác trên thế giới có thể do đối tượng nghiên cứu của chúng tôi là bệnh nhân SSTT nặng và nằm điều trị tại bệnh viện tuyến cuối với nguyên nhân phổ biến nhất là nhiễm trùng. Đánh giá tình trạng dinh dưỡng bằng phương pháp MNA, do các nhà lão khoa quốc tế đưa ra, được xem là tin cậy, được các hiệp hội chuyên ngành dinh dưỡng khuyến nghị sử dụng cho người cao tuổi. Đây là một công cụ xác định người bệnh cao tuổi bị suy dinh dưỡng hoặc có nguy cơ suy dinh dưỡng để đưa ra các can thiệp dinh dưỡng. Những người được sàng lọc bị SDD hoặc có nguy cơ SDD có liên quan đến tỷ lệ mắc bệnh và tỷ lệ tử vong. Công cụ này có giá trị được sử dụng trong bệnh viện, nhà dưỡng lão, tại cộng đồng. MNA xác định SDD hoặc nguy cơ SDD dựa vào các tiêu chí như sụt cân, giảm khẩu phần ăn, chỉ số BMI thấp, có SSTT, khả năng đi lại. Với người bệnh SSTT thường gặp các vấn đề giảm khẩu phần ăn do các vấn đề hạn chế chăm sóc, giảm khả năng chuẩn bị thực phẩm, tự ăn uống, rối loạn nuốt. Nguyên nhân gây giảm khẩu phần ăn có thể do bản thân bệnh SSTT giảm khả năng ăn uống, bệnh lý cấp tính, bệnh mắc kèm làm bệnh nhân giảm cảm giác ngon miệng và cũng có thể do điêu kiện chăm sóc khi nằm viện không được như lúc ở nhà, các món ăn khi nằm viện không phù hợp với khẩu vị của bệnh nhân nển nguy cơ bị SDD sẽ cao hơn khi bệnh nhân nằm điêu trị nôi trú.

Tỉ lệ SDD trong nhóm bệnh nhân SSTT giai đoạn nặng cao hơn các giai đoạn khác có ý nghĩa thống kê theo cả cách đánh giá dinh dưỡng bằng công $c u ̣$ MNA và theo tiêu chuẩn GLIM. Nghiên cứu của chúng tôi cũng phù hợp với nghiên cứu khác trên thế giới cho rằng tình trạng dinh dưỡng càng xấu đi khi sa sút trí tuệ ở giai đoạncàng nặng. Trong nghiên cứu của chúng tổi tỉ lệ SDD ở nhóm có rối loạn nuốt cao hơn nhóm khổng. SDD có ở 50,9\% bểnh nhân có rối loạn nuốt [8] trong nghiên cứu của chúng tôi có tỉ lệ SDD cao hơn có thể là do trong nghiên cứu của chúng tôi tỷ lệ bệnh nhân SSTT giai đoạn nặng chiếm tỉ lệ cao hớn nên bệnh nhân bị rối loạn nuốt có tî lệ nhiều hơn. Kết quả nghiên cứu của chúng tôi bệnh nhân có rối loạn nuốt chiếm tỉ lệ cao hơn của Nguyễn Thanh Bình năm 2018 (77,4\% so với $18,2 \%)$,

Như vậy trong nghiên cứu của chúng tôi đánh giá dinh dưỡng theo công cụ MNA và tiêu chuẩn GLIM đều có tỉ lệ SDD cao. Đánh giá tình trạng dinh dưỡng theo BMI là tiêu chuẩn của Tổ chức y tế thế giới dành cho người $>18$ tuổi, nhưng với đối tượng người cao tuổi theo khuyến cáo của các nhà lão khoa quốc tế nên sử dụng phương pháp sàng loc dinh dưỡng MNA để sàng loc SDD và nguy cơ SDD từ giai đoạn chưa có giảm cân nhằm phát hiện sớm và có kế hoạch can thiệp kịp thời. Tiêu chuẩn GLIM là công cụ chẩn đoán SDD mới nhất mà các hiệp hội dinh dưỡng lâm sàng trên thế giới đã đồng thuận, trong nghiên cứu của chúng tôi cho thấy tỉ lệ SDD khi đánh giá theo GLIM cũng cao gần tướng đương công cụ MNA. Theo khuyến cáo của hội dinh dưỡng lâm sàng châu Âu và hiệp hội Alzheimer đưa ra để làm giảm tỉ lệ SDD, tất cả các BN SSTT cần được sàng lọc, theo dõi và đánh giá tình trạng dinh dưỡng định kỳ, bệnh nhân và người chăm sóc cần được giáo dục dinh dưỡng và tư vấn dinh dưỡng đặc biệt về sụt cân, hành vi ăn uống. SDD là hiện tượng nghiêm trọng, đối với người có nguy cở cần được đánh giá chi tiết về chế độ 
ăn, hành vi ăn uống, nhu cầu hỗ trợ cho ăn, cân can thiệp ngay, và tích cực để phục hồi SDD.

\section{KẾT LUẬN}

Người bệnh sa sút trí tuệ điều trị nội trú có tỉ lệ suy dinh dưỡng cao. Có mốiliên quan giữa tình trạng dinh dưỡng của người bệnh với các yếu tố tuổi, giai đoạn SSTT, rối loạn nuốt. Do vậy, cần quan tâm đánh giá dinh dưỡng và can thiệp dinh dưỡng sớm đối với bệnh nhân SSTT.

\section{TÀI LIỆU THAM KHẢO}

1. Guerchet, M., M. Prince, and M. Prina, Numbers of people with dementia worldwide: An update to the estimates in the World Alzheimer Report 2015. 2020.

2. Miao, J.-P., et al., Comparison of two malnutrition risk screening tools with nutritional biochemical parameters, BMI and length of stay in Chinese geriatric inpatients: a multicenter, crosssectional study. BMJ open, 2019. 9(2): p. e022993.

3. Nguyê̂n Thanh Bình, Đặc điểm lấm sàng và gánh nặng ngươi chăm sóc cho bệnh nhân
Alzheimer giai đoạn nă̆ng, in Luận án Tiến sỹ $Y$ hoc. 2018, Trường Đại học Y Ha Noi: Ha Noi.

4. Shua-Haim, J.R., et al., Depression among Alzheimer's caregivers: Identifying risk factors. American Journal of Alzheimer's Disease \& Other Dementias $\AA$, 2001. 16(6): p. 353-359.

5. Lin, P.-C., et al., Primary diagnoses and outcomes of emergency department visits in older people with dementia: a hospital-based retrospective study in Taiwan. International psychogeriatrics, 2020. 32(1): p. 97-104.

6. Vũ Thị Thu Hà, Tình trạng dinh dưỡng, thói quen ăn uống và khâu phân ăn của bệnh nhân người cao tuối tại Bệnh viện Lão khoa Trung Ương năm 2016, in Khoá luận tốt nghiệp cử nhân Y khoa chuyên ngành dinh dưỡng. 2017, Đại học Y: Hà Nội.

7. Tombini, M., et al., Nutritional status of patients with Alzheimer's disease and their caregivers. Journal of Alzheimer's Disease, 2016. 54(4): p. 1619-1627.

8. Peñalva-Arigita, A., et al., Prevalence of dysphagia in a regional hospital setting: Acute care hospital and a geriatric sociosanitary care hospital: A cross-sectional study. Clinical nutrition ESPEN, 2019. 33: p. 86-90.

\section{MộT Số CHỈ SỐ Sọ MẶT CỦA BỆNH NHÂN Có TƯƠNG QUAN XƯƠ'NG LOẠI II DO KÉM PHÁT TRIỂN XƯƠNG HÀM DƯỚI}

Trần Nguyên Giang1, Nguyễn Thị Thu Phương²

\section{TÓM TẮT}

Nghiên cứu mô tả cắt ngang được thực hiên trên 63 bệnh nhân ở Trung tâm Kĩ thuật cao của Viện Đào tạo Răng Hàm Mặt - trường Đại học Y Hà Nội và Bệnh viện Răng Hàm Mặt Trung ưởng Hà Nội. Các chỉ số nghiên cứu của bềnh nhân đo trên phim chụp sọ nghiêng từ xa kỹ thuật số được phân tích trên Stata 14.0 mô tả giá trị trung bình và kiểm định sự khác biệt giữa nam và nữ về các chỉ số sọ mặt trên phim nghiêng có tương quan xương loại II do kém phát triển xương hàm dưới. Kết quả cho thấy các chỉ số sọ mặt nghiêng của bệnh nhân: góc $A N B=6,88^{\circ} \pm 1,34$; góc $\mathrm{i} / \mathrm{NS}=39,25^{\circ} \pm 6,50$; góc $\mathrm{FMIA}=48,80^{\circ} \pm 6,09$; góc Gl'-Sn-Pg' $=167,74^{\circ} \pm 5,3$; chi số i-NB, M-Me, N-ANS có giá trị lần lượt là $7,70 \pm 1,92,112,68 \pm 8,47$ và $50,94 \pm 4.01(\mathrm{~mm})$ và tỳ lệ tầng mặt N-ANS/N-Melà 0,45 . Các chỉ số trên có sự khác biệt có ý nghĩa thống kê ở hai giới $(p<0,05)$, các chỉ số còn lại sự khác biệt không có ý nghĩa thống kê.

Tư khóa: Trục răng cửa dưới, sai khớp cắn loại II, chỉ số sọ mặt.

\footnotetext{
${ }^{1}$ Bệnh viện Trung ương Thái Nguyên

2Trường Đại hoc Y Hà Nội.

Chịu trách nhiệm chính: Trần Nguyên Giang

Email: trangiangrhm@gmail.com

Ngày nhận bài: 20/8/2021

Ngày phản biện khoa học: 9/9/2021

Ngày duyệt bài: 28/9/2021
}

\section{SUMMARY \\ SOME CRANIOFACIAL INDEXES OF PATIENTS \\ IN THE CORRELATION WITH CLASS II MALOCCLUSION BY UNDERDEVELOPMENT OF LOWER JAW BONE}

The cross-sectional study was conducted on 63 patients at the High-Technology Center of School of Odonto-Stomatology - Hanoi Medical University and Hanoi National Hospital of Odonto-Stomatology. The patient's indicators were measured on digitally tilted cranial imaging. The results were analyzed on Stata 14.0 software, the average values were calculated, and the Mann-Whitney $U$ test was used to test for statistically significant differences between men and women.The results showed that the average value of the patient's tilted cranial indicators wasANB $=6,88^{\circ}$ $\pm 1,34 ; \mathrm{i} / \mathrm{NS}=39,250^{\circ} \pm 6,50 ; \quad \mathrm{FMIA}=48,80^{\circ} \pm 6,09 ; \mathrm{Gl} \mathrm{I}^{\prime} \mathrm{Sn}$ $\mathrm{Pg}^{\prime}=167,74^{\circ} \pm 5,3$. In addition, the $\mathrm{i}-\mathrm{NB}, \mathrm{M}-\mathrm{Me}$, and N-ANS indexes are 7,70 $\pm 1,92,112,68 \pm 8,47$ and $50,94 \pm 4,01(\mathrm{~mm})$, respectively. N-ÁNS/N-Me ratio was 0,45 . All of the above indicators have statistically significant differences in the sexes $(p<0,05)$.

Keywords: Lower incisor axis, class II malocclusion, craniofacial index.

\section{I. ĐẶT VẤN ĐỀ}

Sai khớp cắn loại II là loại sai lệch khớp cắn rất hay gặp ở bệnh nhân nắn chỉnh răng với kiểu xương và răng rất đặc trưng. Có nhiêu nguyên 